\title{
What Characterizes the Polymodal Media of the Mobile Phone? The Multiple Media within the World's Most Popular Medium
}

\author{
Martin Hilbert ${ }^{1, *(1)}$ and Ashwin Aravindakshan ${ }^{2}$ \\ 1 Department of Communication, University of California, Kerr Hall 369, Davis, CA 95616, USA \\ 2 Graduate School of Management, University of California, Davis, CA 95616, USA; aaravind@ucdavis.edu \\ * Correspondence: hilbert@ucdavis.edu
}

Received: 1 June 2018; Accepted: 21 June 2018; Published: 26 June 2018

\begin{abstract}
While the mobile phone is the world's most popular media device, it is actually not one single medium, but is effectively used as a different medium by different user groups. The article characterizes polymodal differences in mobile apps usage among different user groups, including gender, education, occupation, screen size, and price. We monitored the complete app usage of 10,725 smartphone users for one month each (56 million sessions, recording almost 1 million hours). Our key contribution consists in developing and analyzing a theoretical framework to classify the over 16,000 apps used into five categories. Exploring nine research questions we provide a broad characterization by asking who, with which characteristics, uses which kinds of apps in what extensity and intensity? For example, it is not the young and high occupational grades that use the mobile phone as a human-to-machine computer (including gaming and artificial intelligence tools). Large screen size is related to extensive long sessions, while a small screen size is related to intensive frequent usage. The results go beyond providing ample empirical evidence for the inherently polymodal nature of the mobile phone, but also proposes a framework on how to deal with it analytically.
\end{abstract}

Keywords: mobile apps; polymedia; mobile phone; technology adoption; human-to-machine communication; media classification

\section{Introduction}

The mobile phone has become the world's most pervasive and most widely used communication medium. For many around the world, the mobile phone is the only communication medium; worldwide there is some 1 billion fixed-line phones, 2.5 billion TV sets, 3 billion radios, and some 3 billion people using the internet, but over 7 billion mobile phones, more than half of them smartphones [1]. But even in countries like the United States, people have started to spend more time on mobile apps than on watching television [2].

Mobile apps have not only started to replace traditional communication technology, but have also started to replace human-to-human with human-machine communication (endowed with more or less artificial intelligence). Anybody who had to compete with the mobile phone of one's communication partner at the dinner table for communicative attention can attest to this, and this is pervasive: 89\% Americans used their phone during the most recent social gathering [3].

Embracing traditional and new communication functions, digital convergence has converted the mobile phone into a true "polymedia" [4] for "multimodal connectedness" [5]. It essentially joins and complements previously different media. It provides a "media ecology" [6], with the difference of being a single media platform. Despite both this recognition and the importance of the mobile phone 
in today's communication landscape, to date related theoretical frameworks are still missing or mostly anecdotal and not statistically tested. The focus is set on specialized questions, which evades the bird's eyed view required to capture the rich polymodal nature of the mobile phone.

This article presents a broad and statistically testable conceptual framework of the polymodal nature of the mobile phone in terms of how different user groups use it. For this, we work with an extensive dataset from the world's second largest mobile market, India.

We monitored the complete mobile phone usage of 10,725 users from India during a one-month period and recorded 56,290,269 mobile app sessions for a total duration of 974,721 h of interactivity with 16,269 different mobile apps. We elaborate a theoretical framework that allows us to classify all used apps into five mediatic types. We study the technological medium embedded into the social environment of its users by collecting demographic (gender and age), social (marital status, education, occupation), and systems variables (price and screen size of the device). To strengthen this connection between the media and its social embedding, we work with both duration (extensity) and frequency (intensity) of mobile phone usage, since it has been shown that log data on both are complementary in their correlation with socioeconomic, demographic, and other behavioral traits $[7,8]$. We then explore multivariate relationships among these three main groups of variables: type of mediatic use; socio-demographic and technological characteristics; and usage ex- and intensity.

This being said, it is the declared goal of this study to provide a high-level overview and not to look deeply into any particular mediatic type or user group. Instead, we take advantage of our extensive dataset to deliver broad-based empirical evidence of the fact that the mobile phone is effectively used as a different medium by different user groups.

\section{Theoretical Framework: Polymodal Media}

In a classic case of what innovation theory calls a symbiotic merger of previously separated technological trajectories (e.g., [9]), today's mobile phones merges telecommunication, broadcasting, storage, and computation technologies. We follow the literature in the conjecture that a medium is best understood through both its different mediatic functionalities and its social adoption [10-12].

The concept of media ecology embraces this approach. "The word ecology implies the study of environments: their structure, content, and impact on people" [13] (p. 161). As first approximation, the concept of media ecology generalizes McLuhan's “Understanding [of] Media: [as] The Extension of Man" [6]. But—in contrast to other possible formulations like an 'ecology of media' -it goes further and implies that the carrier is at the same time the environment: Media as environments, and environments as media. "We put the word 'media' in the front of the word 'ecology' to suggest that we were not simply interested in media, but in the ways in which the interaction between media and human beings give a culture" [14] (p. 11). Concentrating on the final cultural transformations, media ecologists pursue a very holistic approach, and do not even "see any point in studying media unless one does so within a moral or ethical context" [14] (p. 11).

Half a century later, media scholars renewed the call to "look at the entire range of media as a communicative environment" [15] (p. 124), but felt the need for a new concept to "highlight the unprecedented plurality and proliferation of media ... [and] chose 'polymedia' as a new term to describe the new emerging environment of proliferating communicative opportunities" [16] (p. 125). Like its predecessor, it pursues a very comprehensive understanding of the relation between the social and the technological, with a focus on the emotional, behavioral, and moral relationships that emerge from this interaction [4].

Several concepts have been developed in parallel. "The concept of multimodal connectedness is introduced to examine the whole range of ICTs [information and communication technologies that] complement each other" [5] (p. 75). It "can be defined as the various modalities through which people maintain their connections with each other in everyday life" [5] (p. 79). The concept focuses on a headcount of the number of communication channels used for social interaction among people [17,18]. The slightly broader concept of "media manifold" [19] (p. 220) goes beyond the focus of 
social channels and also considers broadcasting media and other apps. Like multimodal connectedness it focuses on the number of different media used, in this case accounted for by the dimensionality of the figurative manifold.

In an effort to both honor and build on this previous work that spans half a century, we introduce a related, but slightly different concept for our purposes: Polymodal media. It is defined as the multiple modalities with which a single media can be used. In agreement with the literature on media ecology and polymediality, it recognizes that the study of media cannot be done in isolation from its social environment. However, we do not go as far as studying the resulting emotional-, ethical-, and moral effects and relationships that emerge from the interaction, which are the fundamental pursuit of those approaches. For one, theoretically this rather goes back to the original notion of McLuhan that technology is neither blessed nor curses, but is simply a tool [14]. It avoids moral discussions in a first approach to characterizing a media. Furthermore, practically, we prefer to stick with rather objectively variables that allow for a quantitative statistical analysis. Therefore, much in agreement with the literature on the diffusion of innovation and the digital divide, we capture and analyze well-defined socio-demographic aspects of the adoption environment, including affordances, educational and literacy levels, and technological accessibility. In agreement with the literature on multimodal connectedness and media manifolds, the concept of polymodal media focuses on multiplicity of distinct and complementary channels and applications. In contrast to both, it goes beyond counting them, as we develop a taxonomy that qualitatively differentiates among different types such channels and media applications.

In this sense, the concept of polymodal media can be conceptualized as a subpart of the concept of the polymedia. It does not go as far as to necessarily bind the classification of media to some sort of emotional effects and moral results of media interaction. It is however more comprehensive and detailed than multimodal connectedness and media manifolds, since it not only counts, but also qualitatively distinguishes among different kinds of media, while situating them in the social context of its users. In a sense, the focus is less exhaustive with regard to social effects, but richer with regard to technological functionality.

\section{Polymodal Media Taxonomy of Mobile Apps}

We classify different mobile apps along two axis, which we derive from existing literature (for more details, see Supporting Information S.2, Supplementary). Traditionally, a prevalent dichotomy distinguishes between passive audiences with a focus on entertainment, and active audiences with a focus on utility [11]. Passive audiences imply an escapist model of a leisurely way to pass the time, often linked to traditional broadcast like TV or radio [20]. Conversely, active audiences discriminate among media usages [21], often linked to the individual's own needs with utilitarian motives [20,22].

The polymodal diversity provided by the mobile phone breaks the clear tendency that passive usage focuses on leisure and interactive usage on utilitarian purposes. Therefore, we open up these well-established distinctions and split them along the two perpendicular axes as presented in Figure 1. The vertical axis contrasts leisure- versus utilitarian communication. Research has shown that the perception of playfulness and usefulness are important determinants of users' intention to use mobile apps [23]. Mobile phone communication for leisure proposes essentially brings existing forms of entertainment to a mobile format, including human-to-broadcast communication (H2B, including one-directional downstream-heavy apps like music, TV and media player, news- and image apps) and gaming (H2G, including diverse offline and online games). The other side of the axis recognizes that the mobile phone has long been seen by people as a tool for specific utilitarian functions (e.g., [24]). This includes communication with mobile apps that consists of (more or less) intelligent tools (H2T, including maps, planning, shopping, education, and office apps), and those that serve a specific functionality ( $\mathrm{H} 2 \mathrm{~F}$, including phone management and features, dictionary, time, anti-virus, and connectivity helper functions). 


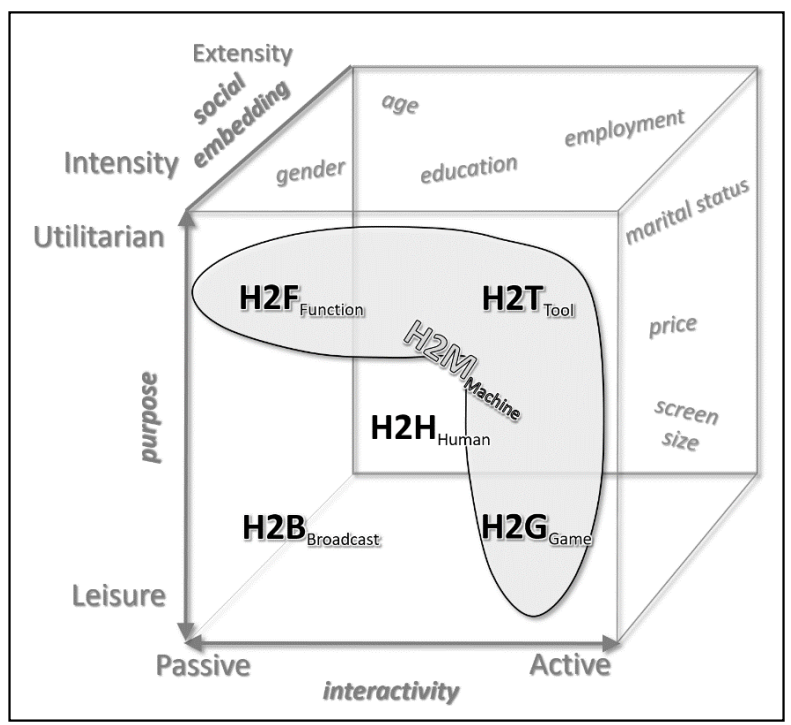

Figure 1. Polymodal media taxonomy of mobile apps along three axes: interactivity = horizontal; purpose $=$ vertical; social embedding $=$ depth .

The horizontal axis distinguishes passive- from active communication. Similar to downstream broadcasting $(\mathrm{H} 2 \mathrm{~B})$, the essential characteristic of passive $\mathrm{H} 2 \mathrm{~F}$ is that the interaction is limited to initial activation or solicitation, followed by a response (in the background or from a server, etc.), while both $\mathrm{H} 2 \mathrm{G}$ and $\mathrm{H} 2 \mathrm{~T}$ require continuous interactivity. For an in-depth discussion of these four mediatic types see Supporting Information S.2 (Supplementary).

The use of mobile phones for the mediation of human-to-human communication $(\mathrm{H} 2 \mathrm{H})$ is naturally placed in the middle between these different extremes. Mobile phone mediated $\mathrm{H} 2 \mathrm{H}$ communication can be both active and passive, as well as for utilitarian and leisure purposes.

The literature has long worked with a dichotomy of communication among humans and machines, which has gone under concepts like 'human' and 'media' interactivity (e.g., [25]), or 'content' and 'interpersonal' interactivity [26]. Simplifying the nuances of different notions in this field, we can aggregate the five mediatic types into human-to-machine communication (H2M), and rather traditional communication functions to the mobile phone, i.e., telephony $(\mathrm{H} 2 \mathrm{H})$ and broadcasting $(\mathrm{H} 2 \mathrm{~B})$ (including radio, TV and written news) (e.g., [21]). As indicated by the gray zone in Figure 1, H2M include $\mathrm{H} 2 \mathrm{~F}, \mathrm{H} 2 \mathrm{~T}$, and $\mathrm{H} 2 \mathrm{G}$, as all of them have only become possible due to the provision of storage and computational capacities by the mobile phone (and more or less artificial intelligence) (for more see Supporting Information S.2, Supplementary).

The depth of Figure 1 recognizes the social embedding of these different functionalities (depth of cube). Following the social stratification hypothesis, the adoption of technology reflects patterns of existing inequalities in society [27] and follow technology appropriation theory [12], we go beyond a binary adoption variable [28]. We track the more fine-tuned scalar variables of communication duration (extensity of media consumption), and communication frequency (intensity of media consumption) (e.g., [29]).

\section{Research Questions}

We elaborate nine research questions to understand who does what on their mobile phone. Each of them identifies some aspects of potential interest, based on anecdotal evidence from previous literature. This might not be enough to formulate strong hypotheses, but will point us to some more interesting questions in this very broad and far-fetched analysis. We follow the variables outlined in Figure 1.

RQ1: Multivariate relationships. The first research question asks about the overall multivariate relations. We aim at identifying those variables that maximally discriminate socio-demographic 
communicator characteristics and different mobile phone mediatic types. Decades of research on the digital divide have shown that the most important socio-demographic characteristics for mobile phone usage are income and education, followed by age [30,31].

Additionally, the literature is clear on the importance of technological characteristics. These are often neglected in human communication research, but are indispensable to consider in a multivariate analysis, as they might confound the role of socio-demographic characteristics. In specific, recent literature has been quite vocal about the importance of mobile phone screen size [32,33]. By now mobile phone screen size variety spans a continuum that reaches from mobile phone watches to tablets.

With regard to mediatic types, previous research suggests that the use of mobile apps for more traditional communication purposes, like $\mathrm{H} 2 \mathrm{H}$ and $\mathrm{H} 2 \mathrm{~B}$, are used quite similarly among different user groups, while more conventional mediatic types, like $\mathrm{H} 2 \mathrm{M}$, shows stark differences between different socio-demographic groups (e.g., [3,34-36].

RQ2: Communication type diversity. If the mobile phone is multiple media in one, it might be that different groups of people appear to use it to a very similar degree when looking at the total usage ex- and intensity, while this aggregated total hides important differences when distinguishing among different mediatic types $(\mathrm{H} 2 \mathrm{H}, \mathrm{H} 2 \mathrm{M}$, etc.). As such, aggregated media consumption statistics would hide interesting variances on the differential usage of different types.

RQ3: Gender. Previous research suggests that women's mobile phone usage is more extensive in voice communication and socialization [35], while there is a male-dominance in gaming [37]. Men also tend to use their mobile phones for business reasons, brief conversations or short information seeking tasks [35,38].

RQ4: Age. Mobile phone usage has traditionally been even more skewed toward younger users than other ICT like computers and the internet $[3,29,34]$. Castells et al. hypothesize that young mobile phone users are "more predisposed toward entertainment" than older users [39] (p. 163), but Park [40] finds that the correlation of young users with instrumental and tool use purposes is stronger than for social-entertainment-based purposes (see also [36]). The usage of traditional mobile phone use, such as for $\mathrm{H} 2 \mathrm{H}$ and $\mathrm{H} 2 \mathrm{~B}$ purposes also requires fewer skills, which facilitates access for older users [3,36].

RQ5: Marital Status. Previous research has detected a stronger correlation of mobile phone users with married individuals than with singles [30,41], which might stem from the constant $\mathrm{H} 2 \mathrm{H}$ communication among family members. Besides that, there is little understanding of this relationship until now.

RQ6: Education. The literature shows a clear positive correlation between educational attainment and mobile phone possession [30,31,34,41]. Pearce and Rice [29] found positive correlations between education and both ex- and intensity of usage while others found a negative one [35,38,41]. Users with higher education seem to use more sophisticated interactive services, including mobile app tools [36]. It seems theoretically justified to deduce that users with very basic educational level and those who are illiterate favor mediatic types that require less input and can be passively consumed, like H2B.

RQ7: Occupation. It has been well documented that the mobile phone is an essential part of the modern workforce. The research found that it is more pervasive among the employed than the unemployed [30], with especial utilitarian importance for workers in higher employment grades [38]. Studies also found that the mobile phone blurs the boundaries between professional and domestic spheres and that users without formal occupation use mobile voice communication extensively for their daily purposes, such as coordination of family and social affairs [42].

RQ8: Price of device. Decades of research on the digital divide have underlined the importance of monetary considerations for ICT usage (e.g., [30,31,38]. High-income groups also use mobile phones both more often and more frequently [29]. Additionally, around three-quarters of cellphone users consider high priced phones to be worth the costs, which suggests that some additional values are being obtained from increased adoption [36]. Beyond overall appropriation, more fine-tuned studies show that users with lower income use their phones more extensively for utilitarian tasks, as they have special needs to solve urgent problems [36]. 
RQ9: Screen size of the device. Over the lifetime of the smartphone, the variable screen size has continuously increased its importance. The literature shows evidence of more sophisticated, more productive, and longer use with larger screen size [32,33]. On the level of distinct app types, it can be hypothesized that smaller screen size is related to more traditional mobile communication, like $\mathrm{H} 2 \mathrm{H}$ and $\mathrm{H} 2 \mathrm{~B}$, while larger screens lend themselves for more processing intensive $\mathrm{H} 2 \mathrm{M}(\mathrm{H} 2 \mathrm{~T}, \mathrm{H} 2 \mathrm{~F}, \mathrm{H} 2 \mathrm{G})$.

\section{Method}

The data are obtained from market research firm situated in India. India is the second largest mobile phone market worldwide (the largest privatized market), with more than $15 \%$ of worldwide phones (some 900,000) (for more, see $[43,44]$ ). The firm randomly chooses domestic smartphone owners and invites them to join the panel. In total, it maintains a panel of mobile usage from around fifty thousand individuals and provided us with data on mobile usage for about a thousand panel members of their pool per month with where selected uniformly at random.

\section{Sampling Procedure}

The panel was formed by an open call for participation on a website ("All smart phone users-Symbian, Android, Blackberry \& iPhone can participate ... [requiring an] active GPRS/data plan throughout the participation period") and by pinpointed recruitment. For the latter, a dataset on smartphone users was obtained from cooperating mobile phone operators and randomly selected individuals were invited to join the panel per text message. As a first step, participants had to complete a socio-demographic profile, including user's device information. This information was used to exclude overrepresented population segments and to approve the participation of underrepresented groups (for more descriptive details on the dataset, see Supporting Information S.1, Supplementary).

Data from final panel members was collected via a metering app installed on the panel member's smartphones. Participants were fully informed that the metering app will track the interactions with their phone and were compensated for the monitoring. Participants had to click on the monitoring app daily and restart their device daily, reconfirming their informed consent. Active participation implies that the app was activated for $20+$ days in a calendar month, with updates successfully sent to the server 4 times a day. Users commit to installing the metering app for one year and were monitored for one continuous month within the year, without knowledge about which month. This randomized strategy aims at avoiding behavioral changes due to awareness of active monitoring. Our data span a period of 11 months, from May 2011 to June 2012, and cover the then-dominant smartphone operating systems Android, Symbian, and BlackBerry. Over this period, a daily average of total of 886 unique users between 16 and 62 years participated successfully in the study (see Supporting Information S.1, Supplementary). It has to be pointed out, that while the data collection occurred some time before the current analysis, our chosen smartphones share fundamentally similar features with modern smartphones, such as a hardware independent Operating System and the possibility to install external apps, which distinguishes them from mere feature phones.

When activated, the metering application captures the behavior of the user on the device in a non-invasive manner. This has a clear advantage over some recent studies that use self-reported survey methods to monitor smartphone usage, as the digital footprint left behind by the user precludes any issue of reporting reliability. On average a user uses 13.4 different apps per user per day (SD 6.5; max 73), executes 186 mobile app session per day, for a total of $3 \mathrm{~h}$ and $15 \mathrm{~min}$ (app use can be overlapping).

While randomly chosen, as so often, the self-selection mechanism leads to the fact that the obtained sample is not necessarily representative of the Indian population (see Supporting Information S.1.1, Supplementary). The size of the sample and the variety of variables allow us to make up for this by employing multivariate tests that control for other socio-demographic covariates. This allows us to obtain insights into relations relative to the controlled variables even for underrepresented groups. As long as the group is large enough to lead to significant results, which is mostly the case (see Table 1 and Supporting Information Table S1, Supplementary). 
Table 1. ANCOVA and MANCOVA with socio-demographic fixed factors and ex- and intensities as dependent variables, each controlled for the remaining six socio-demographic covariates $\left({ }^{*}=p<0.01 ;{ }^{* *}=p<0.001\right.$; E.M. Means $=$ MANCOVA Estimated Marginal Means).

\begin{tabular}{|c|c|c|c|c|c|c|c|c|c|c|c|c|}
\hline & & & \multicolumn{5}{|c|}{ Extensity (Seconds) } & \multicolumn{5}{|c|}{ Intensity (Sessions) } \\
\hline & & & $\mathbf{H} 2 \mathbf{H}$ & H2B & H2T & $\mathrm{H} 2 \mathrm{~F}$ & H2G & $\mathbf{H} 2 \mathbf{H}$ & H2B & H2T & $\mathrm{H} 2 \mathrm{~F}$ & H2G \\
\hline \multicolumn{3}{|c|}{ Plain shares of types } & $28 \%$ & $57 \%$ & $7 \%$ & $5 \%$ & $3 \%$ & $46 \%$ & $30 \%$ & $15 \%$ & $8 \%$ & $1 \%$ \\
\hline \multirow{4}{*}{ Gender } & \multicolumn{2}{|c|}{ ANCOVA } & \multicolumn{5}{|c|}{$\mathrm{F}=2.8, p=0.097$} & \multicolumn{5}{|c|}{$\mathrm{F}=4.5, p=0.033$} \\
\hline & \multicolumn{2}{|c|}{ MANCOVA F sign. } & $71^{* *}$ & $37^{* *}$ & $2, p=0.2$ & $\begin{array}{c}3, p= \\
0.08\end{array}$ & $0, p=0.6$ & $52 * *$ & $23^{* *}$ & $\begin{array}{c}3, p= \\
0.07\end{array}$ & $1, p=0.4$ & $\begin{array}{c}5, p= \\
0.03\end{array}$ \\
\hline & \multirow{2}{*}{ E.M. Means } & Female & 4759 & 4698 & 764 & 469 & 342 & 119.8 & 40.0 & 26.0 & 14.6 & 1.7 \\
\hline & & Male & 3194 & 6714 & 831 & 596 & 366 & 84.0 & 55.4 & 28.7 & 15.5 & 2.3 \\
\hline \multirow{7}{*}{ Age } & \multicolumn{2}{|c|}{ ANCOVA } & \multicolumn{5}{|c|}{$\mathrm{F}=17.6^{* *}$} & \multicolumn{5}{|c|}{$\mathrm{F}=24^{* *}$} \\
\hline & \multicolumn{2}{|c|}{ MANCOVA F sign. } & $4^{*}$ & $17^{* *}$ & $9^{* *}$ & $8^{* *}$ & $13^{* *}$ & $16^{* *}$ & $16^{* *}$ & $3 *$ & $54^{* *}$ & $16^{* *}$ \\
\hline & \multirow{5}{*}{ E.M. Means } & $16-21$ & 3445 & 7236 & 830 & 696 & 417 & 97.7 & 61.1 & 27.5 & 20.9 & 2.7 \\
\hline & & $22-31$ & 3222 & 6672 & 797 & 529 & 304 & 84.2 & 55.5 & 29.1 & 14.2 & 1.9 \\
\hline & & $32-41$ & 2698 & 5490 & 1087 & 693 & 563 & 61.5 & 43.8 & 32.4 & 12.2 & 3.1 \\
\hline & & $42-51$ & 3136 & 5909 & 871 & 592 & 427 & 72.1 & 44.9 & 28.3 & 10.7 & 2.5 \\
\hline & & $52-62$ & 2458 & 1410 & 922 & 606 & 460 & 59.3 & 12.7 & 26.8 & 6.8 & 1.7 \\
\hline \multirow{4}{*}{ Marital Status } & \multicolumn{2}{|c|}{ ANCOVA } & \multicolumn{5}{|c|}{$\mathrm{F}=0.2, p=0.674$} & \multicolumn{5}{|c|}{$\mathrm{F}=6.1, p=0.014$} \\
\hline & \multicolumn{2}{|c|}{ MANCOVA F sign. } & $18^{* *}$ & $\begin{array}{c}5, p= \\
0.02\end{array}$ & $7 *$ & $0, p=0.6$ & $\begin{array}{c}4, p= \\
0.05\end{array}$ & $16^{* *}$ & $\begin{array}{c}1, p= \\
0.44\end{array}$ & $2, p=0.2$ & $1, p=0.5$ & $\begin{array}{c}6, p= \\
0.02\end{array}$ \\
\hline & \multirow[b]{2}{*}{ E.M. Means } & Married & 2957 & 6928 & 878 & 577 & 403 & 77.9 & 53.9 & 29.4 & 15.8 & 2.5 \\
\hline & & Single & 3367 & 6529 & 809 & 598 & 349 & 88.3 & 55.3 & 28.4 & 15.4 & 2.2 \\
\hline \multirow{7}{*}{ Education } & \multicolumn{2}{|c|}{ ANCOVA } & \multicolumn{5}{|c|}{$\mathrm{F}=1.8, p=0.128$} & \multicolumn{5}{|c|}{$\mathrm{F}=3.3^{*}$} \\
\hline & \multicolumn{2}{|c|}{ MANCOVA F sign. } & $10^{* *}$ & $5^{* *}$ & $7^{* *}$ & $2, p=0.1$ & $4^{*}$ & $8^{* *}$ & $4^{*}$ & $16^{* *}$ & $5^{* *}$ & $\begin{array}{c}2, p= \\
0.09\end{array}$ \\
\hline & \multirow{5}{*}{ E.M. Means } & Illiterate & 1462 & 13,197 & 342 & 526 & -121 & 78.6 & 105.5 & 28.7 & 47.2 & 0.2 \\
\hline & & School & 1553 & 7061 & 1255 & 483 & 540 & 57.4 & 53.9 & 45.7 & 15.9 & 3.3 \\
\hline & & Sec./High & 2900 & 7005 & 759 & 559 & 366 & 77.8 & 58.6 & 26.4 & 15.1 & 2.1 \\
\hline & & College & 3255 & 6825 & 813 & 652 & 415 & 81.5 & 55.7 & 26.5 & 15.4 & 2.4 \\
\hline & & (Post)Grad & 3358 & 6458 & 852 & 576 & 341 & 89.2 & 53.4 & 30.0 & 15.6 & 2.3 \\
\hline
\end{tabular}


Table 1. Cont

\begin{tabular}{|c|c|c|c|c|c|c|c|c|c|c|c|c|}
\hline & & & \multicolumn{5}{|c|}{ Extensity (Seconds) } & \multicolumn{5}{|c|}{ Intensity (Sessions) } \\
\hline & & & $\mathrm{H} 2 \mathrm{H}$ & H2B & $\mathrm{H} 2 \mathrm{~T}$ & $\mathrm{H} 2 \mathrm{~F}$ & H2G & $\mathrm{H} 2 \mathrm{H}$ & H2B & $\mathrm{H} 2 \mathrm{~T}$ & $\mathrm{H} 2 \mathrm{~F}$ & H2G \\
\hline \multirow{7}{*}{ Occupation } & \multicolumn{2}{|c|}{ ANCOVA } & \multicolumn{5}{|c|}{$\mathrm{F}=33.4^{* *}$} & \multicolumn{5}{|c|}{$\mathrm{F}=29.5^{* *}$} \\
\hline & \multicolumn{2}{|c|}{ MANCOVA F sign. } & $12 * *$ & $23 * *$ & $5 * *$ & $14^{* *}$ & $6^{* *}$ & $22 * *$ & $24^{* *}$ & $15^{* *}$ & $25^{* *}$ & $6^{* *}$ \\
\hline & \multirow{5}{*}{ E.M. Means } & Student & 3205 & 7076 & 820 & 682 & 395 & 87.2 & 59.0 & 27.6 & 17.8 & 2.5 \\
\hline & & Not empl. & 3666 & 7989 & 841 & 815 & 468 & 83.4 & 65.7 & 27.6 & 18.2 & 2.7 \\
\hline & & Salaried & 3041 & 5807 & 878 & 454 & 343 & 75.4 & 45.5 & 28.7 & 12.5 & 2.1 \\
\hline & & Self empl. & 4311 & 7581 & 794 & 671 & 174 & 81.6 & 52.0 & 21.0 & 12.4 & 1.0 \\
\hline & & Business & 3502 & 6299 & 750 & 482 & 284 & 101.6 & 56.5 & 33.4 & 13.4 & 2.0 \\
\hline \multirow{6}{*}{ Price } & \multicolumn{2}{|c|}{ ANCOVA } & \multicolumn{5}{|c|}{$\mathrm{F}=25.1^{* *}$} & \multicolumn{5}{|c|}{$\mathrm{F}=63.7^{* *}$} \\
\hline & MANCO & F sign. & $14^{* *}$ & $66^{* *}$ & $6^{* *}$ & $15^{* *}$ & $34 * *$ & $17^{* *}$ & $84^{* *}$ & $73 * *$ & $15^{* *}$ & $2, p=0.1$ \\
\hline & \multirow{4}{*}{ E.M. Means } & Low & 2675 & 8937 & 833 & 423 & 100 & 101.3 & 79.4 & 39.6 & 19.3 & 1.9 \\
\hline & & Medium & 3429 & 6639 & 840 & 677 & 425 & 81.8 & 56.7 & 26.2 & 14.9 & 2.3 \\
\hline & & Expensive & 3176 & 6416 & 857 & 524 & 342 & 87.6 & 49.2 & 29.5 & 14.8 & 2.3 \\
\hline & & Very exp. & 3290 & 5643 & 737 & 623 & 426 & 78.4 & 45.9 & 26.1 & 16.1 & 2.4 \\
\hline \multirow{5}{*}{ Screen } & \multicolumn{2}{|c|}{ ANCOVA } & \multicolumn{5}{|c|}{$\mathrm{F}=4.9^{*}$} & \multicolumn{5}{|c|}{$\mathrm{F}=4.6^{* *}$} \\
\hline & \multicolumn{2}{|c|}{ MANCOVA F sign. } & $52 * *$ & $42 * *$ & $164^{* *}$ & 100 ** & $148 * *$ & $18^{* *}$ & $42 * *$ & $80 * *$ & $96^{* *}$ & $80^{* *}$ \\
\hline & \multirow{3}{*}{ E.M. Means } & Small & 3289 & 6786 & 691 & 468 & 269 & 88.6 & 55.1 & 26.6 & 13.2 & 1.7 \\
\hline & & Medium & 2996 & 6776 & 969 & 677 & 413 & 83.2 & 57.7 & 32.7 & 18.8 & 2.9 \\
\hline & & Large & 4687 & 4177 & 1253 & 1281 & 1017 & 64.0 & 31.0 & 20.0 & 15.1 & 3.6 \\
\hline
\end{tabular}




\section{Measures}

The two key dependent variables in the following analyzes are the daily mean values of mobile app usage extensity, measured in the duration of sessions in seconds, and intensity, measured in the number of sessions). A session was recorded by the installed metering app when an app was activated by the user (not running in the background). The daily mean per user was calculated for all days that at least one session has been recorded for the phone $(\mathrm{M}=27.7$ days per user, $\mathrm{SD}=4.8)$.

Our classification of the 16,269 used apps into the five mediatic types from Figure 1 was guided by the rather automatically provided rubrics used in app stores, like "Productivity", "Utility", "Music", and "Games" (resulting in 125 different rubrics), but was manually revised for consistency (see Supporting Information S.2, Supplementary). We then classified those rubrics into our 5 types by hand (sometimes we had to split a rubric like "adult apps").

For a complete list of our seven independent variables see Table 1. Gender $\left(\mathrm{N}_{\text {male }}=10,367\right)$, age $\left(\mathrm{N}_{16-21}=3013 ; \mathrm{N}_{22-31}=5701 ; \mathrm{N}_{32-41}=452 ; \mathrm{N}_{42-51}=1503\right)$; and marital status $\left(\mathrm{N}_{\text {single }}=7575\right)$ are standard. Seven original choices for education were merged into five groups, including illiterate $(N=7)$; some school (merging up to 4 years and 5-9 years: $N=63$ ), Secondary and Higher School Certificate $(N=1714)$, some College (but not graduated; $(N=2713)$, and College graduates and Post Graduates (merging professional and general). Five occupational groups were created from originally 22 choices, and coded from lower to higher: Students $(N=4963)$, housework/temporally not employed $(N=755)$, salaried $(N=3313)$, self-employed professional $(N=173)$, and business owner/industrialist. Both price and screen size were inferred from the brand and version of the phone reported. Price of the device was classified in four groups, from low (4-6 k rupees $\approx$ USD 71-110; $N=1094)$, medium $(\approx$ USD 110-180, $N=4428)$, expensive $(\approx$ USD 180-270; $N=3553)$, and above very expensive. Screen size was grouped in screens with less than 3 inch diagonal (small, $N=5955$ ), between 3 and 3.5 inch (medium, $N=4212$ ) and more than 3.5 inches. As a reference, 3.5 inch was the screen size of iPhones $1-4$.

\section{Statistical Tests}

All bivariate correlations were far below the accepted threshold of multicollinearity [45]. The most worrisome methodological particularity stems from the well-known fact that digital media usage usually follows a power law like distribution. After extensive tests of the data we decided to keep the entire sample and not to use log-transformations, but to employ nonparametric statistical tests (see Supporting Information S.3.1, Supplementary). Our standard go-to test is the nonparametric Kruskal-Wallis test, which safeguards against non-normality, and for multivariate analysis we pay special attention to Pillai's criterion, which is considered to be robust against unequal covariance matrices [45].

\section{Results}

The results are summarized in Table 1 . The first line shows that rather traditional mediatic types, like $\mathrm{H} 2 \mathrm{H}$ and $\mathrm{H} 2 \mathrm{~B}$, are the most ex- and intensively used apps overall. This contrasts with the finding that $80 \%$ of all apps used by all users belong to H2M communication (H2T: 20\%, H2F: 23\%; H2G: 37\%; against $\mathrm{H} 2 \mathrm{H}: 7 \%$; H2B: $13 \% ; p<0.001$ ).

RQ1: Multivariate relationships. We chose canonical correlation analysis to evaluate the multivariate shared relationship between the chosen user characteristics and the five mediatic types. Canonical correlation analysis represents the highest level of the general linear model and subsumes both univariate and multivariate methods as special cases ([46]; for a good overview [47]). In essence, it creates two linear equations in such a way as to yield the largest possible correlation between the two resulting synthetic variables (in our case communicator characteristics and communication type). That is, the variance in one of the observed variables is combined to maximally correlate with the combined variance in the other observed variable set. 
Both mobile app communication extensity and intensity were evaluated separately in Figures $2 \mathrm{a}$ and $2 \mathrm{~b}$. For both tests the full model across all functions were highly significant $(p<0.001)$ using Pillai's trace (EX: Pillai's trace $=0.12095, \mathrm{~F}(\mathrm{DF} 35,53,585)=37.9$; IN: Pillai's trace $=0.1544$, $\mathrm{F}(\mathrm{DF} 35,53,585)=48.8)$. In both cases the dimension reduction analysis yielded four highly significant functions $(p<0.001)$ (for more details see Supporting Information S.3.2, Supplementary). In terms of the squared canonical correlation coefficients, the first four functions together explained $11.9 \%$ of the shared variance for extensity and $15.3 \%$ for intensity. The total canonical communality coefficients $\left(\mathrm{h}^{2}\right)$ for each variable represent the amount of variance in the observed variable that was reproducible across the four functions (Figure 2 and Table S6 in Supplementary).

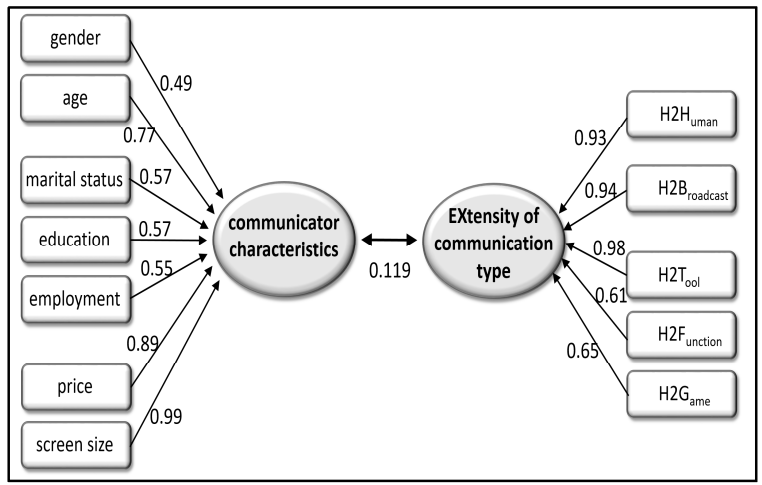

(a)

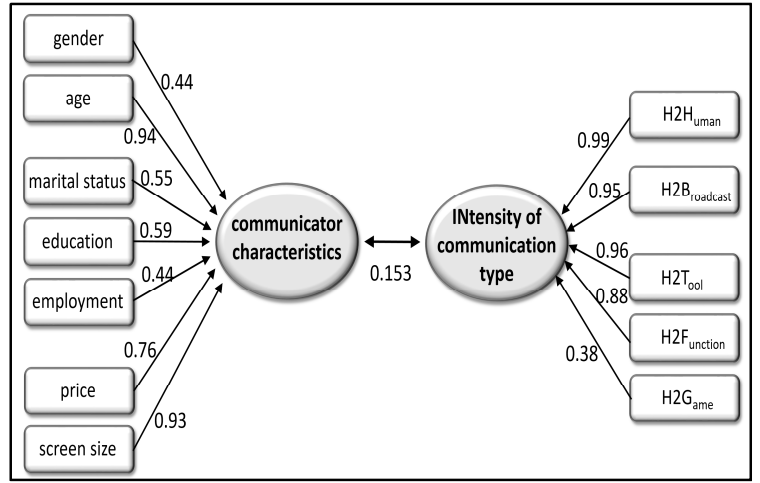

(b)

Figure 2. Canonical correlation analysis model for (a) extensity, and (b) intensity.

In contrast to traditional digital divide literature [30,31], both the price and education are not the two main explanatory variables, even so mobile phone price plays a quite important role to explain differential usage extensity. In agreement with what was to be expected, age and screen size are the most important communicator characteristics.

In terms of the synthetic variable that discriminates among mediatic types, we see that both $\mathrm{H} 2 \mathrm{H}$ and $\mathrm{H} 2 \mathrm{~B}$ play a prominent role (together with $\mathrm{H} 2 \mathrm{~T}$ ). $\mathrm{H} 2 \mathrm{~F}$ and (somewhat surprisingly) $\mathrm{H} 2 \mathrm{G}$ are not as useful to maximally discriminate among different user profiles and usage types.

RQ2: Communication type diversity. As shown in Table 1, of the 14 univariate ANCOVAs, which test the relation between a chosen fixed factor the total ex- and intensity (controlling for the remaining six socio-demographic variables), more than 1 in 3 is not significant (5 out of 14), while $50 \%$ of them at the $p<0.001$ mark. For the 70 multivariate MANCOVAs, which test the relation between a chosen fixed factor the ex- and intensity among the five different mediatic types (controlling for the remaining six socio-demographic variables), less than 1 in 4 are not significant, while over $70 \%$ are at the $p<0.001$ mark. As such, we can confirm that on average the relationships between socio-demographic variables and ex- and intensity are less significant for total mobile phone usage than for the different mediatic types used on mobile phones.

RQ3: Gender. Table 1 shows that the univariate ANCOVA found no significant difference in marginal means of both total ex- and intensity with regard to gender (EX: $\mathrm{F}=2.8, p=0.097 ; \mathrm{IN}: \mathrm{F}=4.5$, $p=0.033)$, that is, after all the effects of all six other socio-demographic variables have been accounted for. At the same time, women make more ex- and intensive use of $\mathrm{H} 2 \mathrm{H}$ communication (EX: $\mathrm{F}=71$, $p<0.001 ; \mathrm{IN}: \mathrm{F}=52, p<0.001$ ) (see Table 1 for details on the $\mathrm{F}$ and $p$ values).

RQ4: Age. In contrary to expectations, young users do not show more usage. Also contrary to previous findings, our digital footprint shows that young users use the mobile phone more extensively for more traditional $\mathrm{H} 2 \mathrm{H}$ and $\mathrm{H} 2 \mathrm{~B}$, while older users use mobile tools $(\mathrm{H} 2 \mathrm{~T})$ and are avid gamers $(\mathrm{H} 2 \mathrm{G})$. 
RQ5: Marital Status. For both ex- and intensity of usage, we find a highly significant difference in the opposite direction than what was suggested by previous literature (see Table 1 for $\mathrm{F}$ and $p$ values): singles use $\mathrm{H} 2 \mathrm{H}$ more than married couples. None of the other mediatic types shows significant differences when controlling for the remaining six socio-demographic variables.

RQ6: Education. Table 1 shows that the MANCOVA detects significantly different estimated marginal means for H2T (except IN H2G), but Table 1 and Figure 3 shows that there is no monotone in- or decreasing tendency among educational levels. A posthoc partial correlation between increasing educational level and H2T (controlling for the remaining six socio-demographic variables) is significant and shows a positive correlation with extensity $\left(\mathrm{r}_{\text {part }}(10,717)=0.027, p=0.005\right)$ and intensity $\left(\mathrm{r}_{\text {part }}(10,717)=0.043, p<0.001\right)$ and a negative correlation with H2B for both extensity $\left(\mathrm{r}_{\text {part }}(10,717)=0.043, p=<0.001\right)$ and intensity $\left(\mathrm{r}_{\text {part }}(10,717)=-0.032, p=0.001\right)$. Figure 3 reveals a striking difference in mobile phone uses by the illiterate. Unfortunately, only 7 of our 10,725 subjects are illiterate (illiteracy faces obvious challenges for study recruitment), which does not lead to significant results.

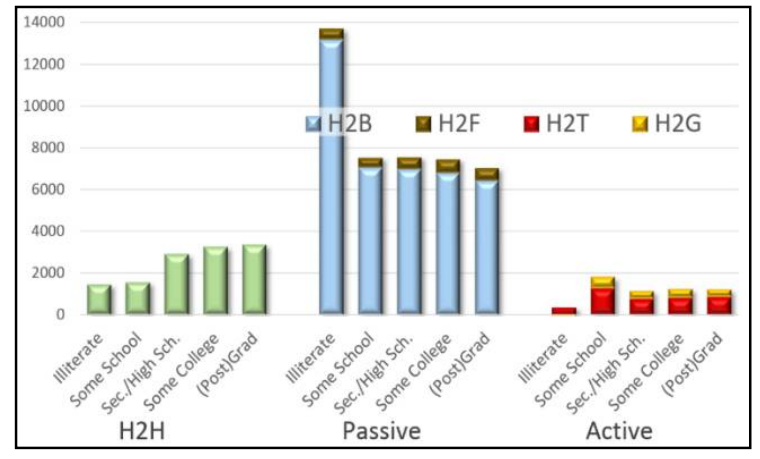

(a)

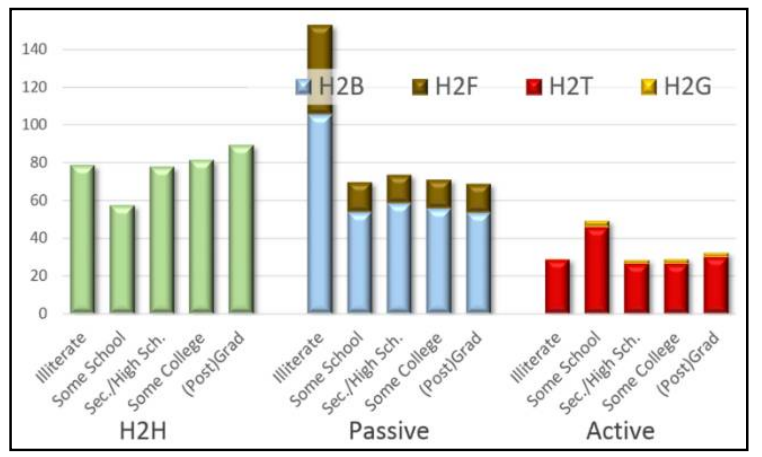

(b)

Figure 3. Educational level as fixed factor and six covariates; MANCOVA estimated marginal means of communication type per user per day: (a) extensity; (b) intensity.

RQ7: Occupation. In general, higher occupational grades have more ex- and intensive H2T (extensity: $\mathrm{r}_{\text {part }}(10,717)=-0.018, p=0.060$; intensity: $\left.\mathrm{r}_{\text {part }}(10,717)=0.051, p<0.001\right)$. Contrary to expectations, we also find that higher occupational groups use $\mathrm{H} 2 \mathrm{H}$ more ex- and intensively (controlled for income and education, etc.).

RQ8: Price of device. Surprisingly, we find that more expensive mobile phones do not show more ex- and intensive usage (extensity: $r_{\text {part }}(10,717)=-0.078, p<0.001$; intensity: $r_{\text {part }}(10,717)=-0.096$, $p<0.001$ ) (see also Figure 4a). At the same time we find that cheaper phones are employed more for utilitarian tool use (with H2T: extensity: $\mathrm{r}_{\text {part }}(10,717)=-0.021, p<0.021$; intensity: $\left.\mathrm{r}_{\text {part }}(10,717)=-0.074, p<0.001\right)$.

RQ9: Screen size of device. The partial controlled correlation shows a negative relation between screen size and communication intensity $\left(9 \mathrm{aIN} \mathrm{r}_{\text {part }}(10,717)=-0.024, p=0.012\right)$. The main culprit is the role of traditional $\mathrm{H} 2 \mathrm{H}$ and $\mathrm{H} 2 \mathrm{~B}$ (extensity: $\mathrm{r}_{\text {part }}(10,717)=-0.036, p<0.001$; intensity: $\left.\mathrm{r}_{\text {part }}(10,717)=-0.006, p<0.001\right)$. We find the largest effect size among all of our tests by the finding that larger screens are linked to more ex- and intensive H2M (extensity: $\mathrm{r}_{\text {part }}(10,717)=0.227, p<0.001$; intensity: $\left.r_{\text {part }}(10,717)=0.106, p<0.001\right)$ (Figure $\left.4 b\right)$. Post hoc tests show that this relationship is also significant for each of the members of H2M, namely H2T, H2F and H2G. 


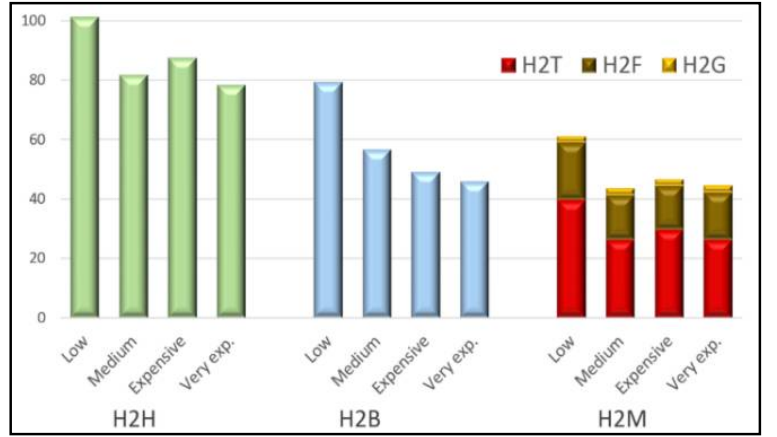

(a)

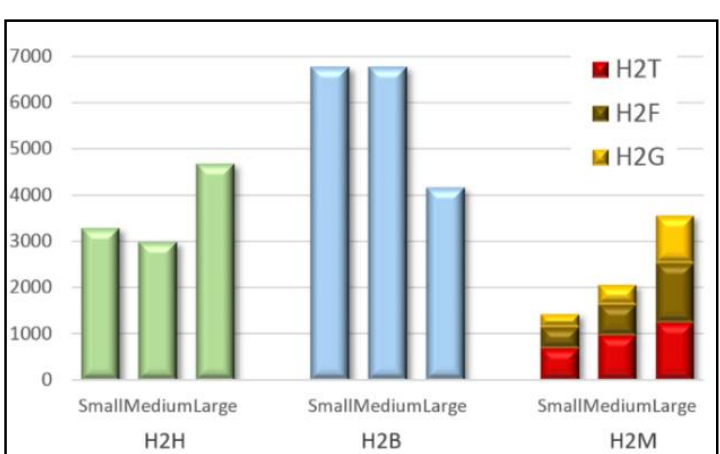

(b)

Figure 4. MANCOVA estimated marginal means of communication type per user per day, with six covariates for fixed factor (a) price of device for intensity; and (b) screen size for extensity.

\section{Discussion}

Our study has provided broad-based and diverse empirical evidence that the mobile phone is clearly used as a different media by different user groups. Table 2 presents a rather qualitative interpretation of the quantitative results presented in Table 1. For example, it illustrates that the mobile phone is used as a traditional $\mathrm{H} 2 \mathrm{H}$ medium by women, young users, singles, highly educated, with an independent occupation, while men and the less educated use it as a H2B entertainment medium. Table 2 underlines the unexpected finding that none of the $\mathrm{H} 2 \mathrm{M}$ usages $(\mathrm{H} 2 \mathrm{~T}+\mathrm{H} 2 \mathrm{~F}+\mathrm{H} 2 \mathrm{G})$ is significantly male dominated, and that tool use $(\mathrm{H} 2 \mathrm{~T})$ is mainly used by lower occupational grades. Also, the profile of the user group that uses the mobile phone as a gaming medium $(\mathrm{H} 2 \mathrm{G})$ is unexpected, as it is not made of young, single men. Additionally, Table 2 shows that our two technological variables (price and screen size) are the only ones that allow to distinguish between differences in ex- and intensity of mobile phone usage. For example, for all types but H2G, a large screen size is related to extensive long sessions, while a small screen size is related to intensive frequent usage. Socio-demographic characteristics do not allow to distinguish among these differences in social adoption.

Table 2. Broad characterization of the polymodal media of the mobile phone. Note: Bold/italic: emphasizes differences between ex- and intensity; ( .. ): weak significance; mixed: non-linear relationship; independent: not-salaried; individually: student + not empl. + self empl.

\begin{tabular}{ccccccccc}
\hline & & Gender & Age & Marital & Education & Occupation & Price & Screen \\
\hline \multirow{2}{*}{ H2H } & EX & female & young & single & educated & independent & not low & large \\
& IN & female & young & single & educated & independent & low & small \\
\hline \multirow{2}{*}{ H2B } & EX & male & young & (married) & uneducated & individually & lower & large \\
& IN & male & young & - & illiterate & none/student & lower & not large \\
\hline \multirow{2}{*}{ H2T } & EX & - & older & married & school & lower grades & not very exp. & larger \\
& IN & (male) & not-mid & - & school & not self-empl. & low & not large \\
\hline \multirow{2}{*}{ H2F } & EX & (male) & mixed & - & - & individually & not low & larger \\
& IN & - & middle & - & illiterate & none/student & low & medium \\
\hline \multirow{2}{*}{ H2G } & EX & - & older & (married) & mixed & lower grades & not low & larger \\
& IN & (male) & mixed & (married) & mixed & lower grades & not low & larger \\
\hline
\end{tabular}

The summary of Table 2 underlines our finding from RQ2, which has shown that any attempt to aggregate its heterogeneous communication functionality into one single indicator will miss important aspects of user diversity and communication variety. For example, our univariate tests of aggregate ex- and intensity of general mobile phone usage for gender and marital status turned out 
to not detect any significant differences between men and women, or between married and singles. By developing and applying a taxonomy of different mediatic types we were able to show that this seeming homogeneity was hiding significant differences in terms of different kinds of apps that are used by different user groups. Women use their phone much more often for human-to-human communication while men use it more for broadcasting purposes (see Figure 5). On the aggregate level, both tendencies counterbalance each other, which leads to a deceptive homogeneity if we neglect the inherent polymodal nature of the mobile phone.

Our study has shown that mobile apps both extend some well-known aspects of media use while they also introduce just as many unexpected and surprising patterns. While it is beyond the scope of this broad study to delve deeper into the details, several of the counter-intuitive findings are yet to be explored by more in depth research.

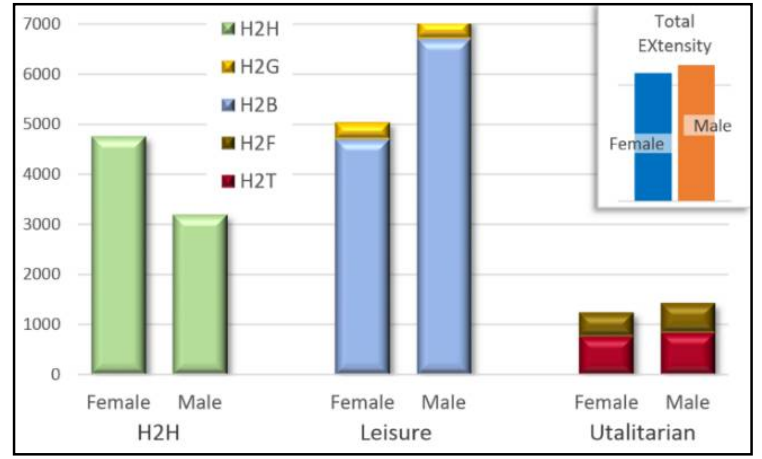

(a)

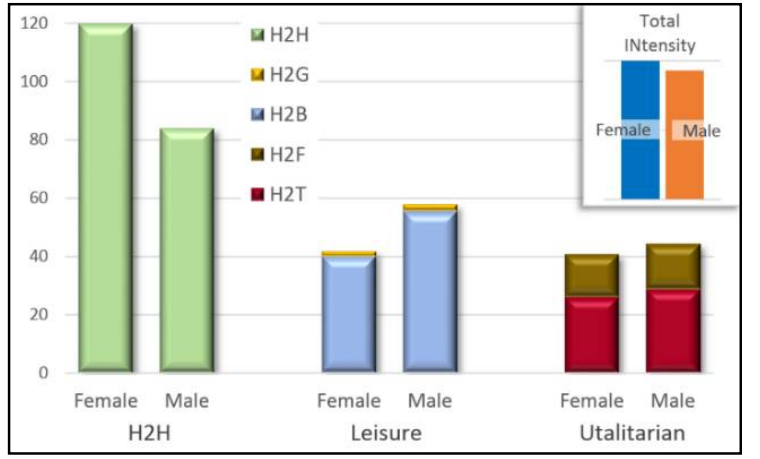

(b)

Figure 5. Gender as fixed factor and six covariates; MANCOVA estimated marginal means of communication type per user per day: (a) extensity; (b) intensity.

\section{Limitations}

The first and unavoidable limitation is inherently linked to the main goal of this study: the development of a broad and statistically testable conceptual framework. Any chosen theoretical framework will inevitably influence the result of the subsequent tests. We followed insights from established theoretical literature, but are very aware that other taxonomies could have been developed, which would have shed a different light on the issue. After much back and forth, we feel that the incipient stage of our understanding results in a typical chicken and egg problem. Developing adequate taxonomies to describe the phenomena goes hand in hand with deepening our understanding of it, which is what this study aims at. Based on the gained insights, future studies might develop a modified framework. Unsupervised machine learning tools might be useful in this task. Based on our particular theoretical framework, we also found that there are important aspects we must have missed. The squared canonical correlation coefficients that maximally discriminates between mediatic types and communicator characteristics captured only $12-15 \%$ of the shared variance. This must not be the fault of the mobile app taxonomy, but can also stem from the lack of inclusion of further socio-demographic variables (e.g., like ethnic origin and culture). We suspect that the additional of complementary technological characteristics can quickly boost the strength of this overall correlation.

Third, our dataset stems from India. There might be important cultural characteristics that influence our results. These are not considered here and therefore the results might not be generalizable to other countries. On the upside, India is the second biggest mobile phone market in the world, and therefore deserves its own treatment.

Finally yet importantly, the most obvious limitation refers to the incessant technological progress of mobile telephony. Shortly after our sample period, the iPhone took over the world market. User behavior might have changed since then and it is probable that it is still changing. We still consider our findings very insightful for two reasons. For one, any kind of smartphone shares 
important similarities with future generation smartphones, including the hardware-independent operating system and the possibility to install third party apps. Besides, our main contributions aims to push conceptual frameworks. While the fast pace technological change will surely change the proportional importance and the specificity of particular findings, it should not as easily alter the proposed theoretical framework for the polymodal media constituted by the mobile phone. In this sense, this study provides a benchmark for future generations of studies.

Supplementary Materials: The following are available online at http:/ /www.mdpi.com/2414-4088/2/3/37/s1, Supporting information: What characterizes the polymodal media of the mobile phone? The multiple media within the world's most popular medium.

Author Contributions: M.H. designed and carried out the analysis and wrote the article. A.A. obtained and curated the data, discussed the analysis, and revised the manuscript.

Conflicts of Interest: The authors declare no conflicts of interest.

\section{References}

1. International Telecommunication Union (ITU). World Telecommunication/ICT Indicators Database; ITU: Geneva, Switzerland, 2015.

2. Khalaf, S. The Cable Industry Faces the Perfect Storm: Apps, App Stores and Apple; Flurry Analytics: San Francisco, CA, USA, 2015.

3. Lee, R.; Zickuhr, K. Americans' Views on Mobile Etiquette; Pew Research Center: Washington, DC, USA, 2015.

4. Madianou, M. Smartphones as Polymedia. J. Comput. Mediat. Commun. 2014, 19, 667-680. [CrossRef]

5. Schroeder, R. Mobile phones and the inexorable advance of multimodal connectedness. New Media Soc. 2010, 12, 75-90. [CrossRef]

6. McLuhan, M. Understanding Media: The Extensions of Man; Sphere Books: London, UK, 1964.

7. Blumenstock, J.E.; Eagle, N. Divided We Call: Disparities in Access and Use of Mobile Phones in Rwanda. Inf. Technol. Int. Dev. 2012, 8, 1-16.

8. Frias-Martinez, V.; Virseda, J. Cell Phone Analytics: Scaling Human Behavior Studies into the Millions. Inf. Technol. Int. Dev. 2013, 9, 35-50.

9. Arthur, W.B. The Nature of Technology: What It Is and How It Evolves; Free Press: New York, NY, USA, 2009.

10. Perse, E.M.; Dunn, D.G. The utility of home computers and media use: Implications of multimedia and connectivity. J. Broadcast. Electron. Media 1998, 42, 435-456. [CrossRef]

11. Ruggiero, T.E. Uses and Gratifications Theory in the 21st Century. Mass Commun. Soc. 2000, 3, 3-37. [CrossRef]

12. Wirth, W.; Von Pape, T.; Karnowski, V. An Integrative Model of Mobile Phone Appropriation. J. Comput. Mediat. Commun. 2008, 13, 593-617. [CrossRef]

13. Postman, N. The Reformed English Curriculum. In High School 1980; the Shape of the Future in American Secondary Education; Eurich, A.C., Ed.; Pitman Publishing Corp: New York, NY, USA, 1970; pp. 160-168.

14. Postman, N. The Humanism of Media Ecology Keynote. In Proceedings of the Media Ecology Association, New York, NY, USA, 16-17 June 2000.

15. Madianou, M.; Miller, D. Migration and New Media: Transnational Families and Polymedia; Routledge: Abingdon, UK, 2013.

16. Madianou, M.; Miller, D. Polymedia: Towards a new theory of digital media in interpersonal communication. Int. J. Cult. Stud. 2013, 16, 169-187. [CrossRef]

17. Chan, M. Multimodal Connectedness and Quality of Life: Examining the Influences of Technology Adoption and Interpersonal Communication on Well-Being across the Life Span. J. Comput.-Mediat. Commun. 2015, 20, 3-18. [CrossRef]

18. Meng, J.; Williams, D.; Shen, C. Channels matter: Multimodal connectedness, types of co-players and social capital for Multiplayer Online Battle Arena gamers. Comput. Hum. Behav. 2015, 52, 190-199. [CrossRef]

19. Couldry, N. The necessary future of the audience ... and how to research it. In The Handbook of Media Audiences; Nightingale, V., Ed.; John Wiley \& Sons: Cambridge, UK, 2011; pp. 213-229.

20. Rubin, A.M. Ritualized and Instrumental Television Viewing. J. Commun. 1984, 34, 67-77. [CrossRef]

21. Kiousis, S. Interactivity: A concept explication. New Media Soc. 2002, 4, 355-383. [CrossRef] 
22. Katz, E.; Blumler, J.G.; Gurevitch, M. Uses and Gratifications Research. Public Opin. Quart. 1973, 37, $509-523$. [CrossRef]

23. Verkasalo, H.; López-Nicolás, C.; Molina-Castillo, F.J.; Bouwman, H. Analysis of Users and Non-users of Smartphone Applications. Telemat. Inform. 2010, 27, 242-255. [CrossRef]

24. Katz, J.E. Social and organizational consequences of wireless communications. Telemat. Inform. 1997, 14, 233-256. [CrossRef]

25. Stromer-Galley, J. On-line interaction and why candidates avoid it. J. Commun. 2000, 50, 111-132. [CrossRef]

26. Massey, B.L.; Levy, M.R. Interactivity, Online Journalism, and English-Language Web Newspapers in Asia. Journal. Mass Commun. Quart. 1999, 76, 138-151. [CrossRef]

27. Arie, Y.; Mesch, G.S. The Spatial and Social Network Dimensions of Mobile Communication A Test of the Social Stratification and Social Diversification Hypotheses. Commun. Res. 2015, 43, 713-734. [CrossRef]

28. Van Deursen, A.J.; van Dijk, J.A. The digital divide shifts to differences in usage. New Media Soc. 2014, 16, 507-526. [CrossRef]

29. Pearce, K.E.; Rice, R.E. Digital Divides from Access to Activities: Comparing Mobile and Personal Computer Internet Users. J. Commun. 2013, 63, 721-744. [CrossRef]

30. Rice, R.E.; Katz, J.E. Comparing internet and mobile phone usage: Digital divides of usage, adoption, and dropouts. Telecommun. Policy 2003, 27, 597-623. [CrossRef]

31. Hilbert, M. When is Cheap, Cheap Enough to Bridge the Digital Divide? World Dev. 2010, 38, 756-770. [CrossRef]

32. Chae, M.; Kim, J. Do size and structure matter to mobile users? Behav. Inf. Technol. 2004, 23, $165-181$. [CrossRef]

33. Maniar, N.; Bennett, E.; Hand, S.; Allan, G. The Effect of Mobile Phone Screen Size on Video Based Learning. J. Softw. 2008, 3, 51-61. [CrossRef]

34. Ishii, K. Internet use via mobile phone in Japan. Telecommun. Policy 2004, 28, 43-58. [CrossRef]

35. Wei, R.; Lo, V.-H. Staying connected while on the move Cell phone use and social connectedness. New Media Soc. 2006, 8, 53-72. [CrossRef]

36. Smith, A. U.S. Smartphone Use in 2015; Pew: Washington, DC, USA, 2015.

37. Lenhart, A. Teens, Social Media \& Technology Overview 2015; Pew Research Center: Washington, DC, USA, 2015.

38. Leung, L.; Wei, R. More than Just Talk on the Move: Uses and Gratifications of the Cellular Phone. Journal. Mass Commun. Quart. 2000, 77, 308-320. [CrossRef]

39. Castells, M.; Fernandez-Ardevol, M.; Qiu, J.L.; Sey, A. Mobile Communication and Society: A Global Perspective; The MIT Press: Cambridge, MA, USA, 2009.

40. Park, Y.J. My whole world's in my palm! The second-level divide of teenagers' mobile use and skill. New Media Soc. 2014, 17, 977-995. [CrossRef]

41. Van den Berg, P.E.W.; Arentze, T.A.; Timmermans, H.J.P. New ICTs and social interaction: Modelling communication frequency and communication mode choice. New Media Soc. 2012, 14, 987-1003. [CrossRef]

42. Schwanen, T.; Kwan, M.-P. The Internet, mobile phone and space-time constraints. Geoforum 2008, 39, 1362-1377. [CrossRef]

43. Desai, A. India's Telecommunications Industry: History, Analysis, Diagnosis; SAGE: Newcastle upon Tyne, UK, 2006.

44. Doron, A. The Great Indian Phone Book; Harvard University Press: Cambridge, MA, USA, 2013.

45. Tabachnick, B.G.; Fidell, L.S. Using Multivariate Statistics; Pearson Education: New York, NY, USA, 2013.

46. Knapp, T.R. Canonical correlation analysis: A general parametric significance-testing system. Psychol. Bull. 1978, 85, 410-416. [CrossRef]

47. Sherry, A.; Henson, R. Conducting and interpreting canonical correlation analysis in personality research: A user-friendly primer. J. Personal. Assess. 2005, 84, 37-48. [CrossRef] [PubMed]

(C) 2018 by the authors. Licensee MDPI, Basel, Switzerland. This article is an open access article distributed under the terms and conditions of the Creative Commons Attribution (CC BY) license (http://creativecommons.org/licenses/by/4.0/). 